\title{
CORRELAÇÃO DO COMPORTAMENTO MECÂNICO E CÍCLICO COM A RESISTÊNCIA À FADIGA DE UM AÇO BAIXA LIGA*
}

Fabio do Prado Verderano ${ }^{1}$ William Naville ${ }^{2}$

\section{Resumo}

A partir de corpos de prova de uma chapa de aço baixa liga NBR 6656 grau LNE 26, realizou-se a caracterização microestrutural, levantamento do perfil de dureza ao longo da espessura da chapa, ensaios de tração monotônicos, cíclicos de fadiga e análises fractográficas. Concluiu-se que, nas extremidades da espessura da amostra, o valor da dureza é maior, indicando que quando a chapa foi laminada as superfícies em contato com os rolos de laminação sofreram encruamento, aumentando a dureza nessa região. A microestrutura encontrada e o grau das inclusões presentes na amostra são compatíveis para o material, bem como as propriedades mecânicas monotônicas, que estão de acordo com a especificação. Por meio de ensaios de fadiga de baixo ciclo, encontrou-se uma boa correlação entre as propriedades monotônicas e cíclicas do material para a proposição da equação de Basquin, considerando-se dados seguros, quando utilizado os primeiros vinte ciclos do ensaio de fadiga para estabilização de cada corpo de prova. Verificando-se a seção transversal da fratura do corpo de prova, observa-se que o mecanismo de falha do material ocorreu a partir do aparecimento de trincas na interface ferrita-cementita com propagação transgranular até a fratura final.

Palavras-chave: Comportamento mecânico; Aço baixa liga; Fadiga de baixo ciclo.

\section{CORRELATION BETWEEN MECHANICAL AND CYCLIC BEHAVIOR WITH THE FATIGUE RESISTENCE OF A LOW ALLOY STEEL}

\section{Abstract}

From specimens of a low-alloy steel plate NBR 6656 grade LNE 26, was performed the microstructural characterization, hardness profile survey along the plate thickness, monotonic tensile tests, cyclic fatigue and fractográficas analysis. Was concluded that at ends of the sample thickness, the hardness value is higher, indicating that when the sheet was laminated surfaces in contact with the lamination rolls have undergone work hardening by increasing the hardness in that region. The microstructure found, and the level of inclusions present in the sample are compatible with the material and the monotonic mechanical properties, which are in agreement with the specification. Through low cycle fatigue tests, we found a good correlation between the monotonic and cyclic properties of the material to the proposition of Basquin equation, considering data safe when used the first twenty cycles of the endurance test for stabilization of each specimen. The cross-section analyses of the specimen fracture showed that the material failure mechanism occurred from cracks arising in the ferrite-cementite interface and transgranular propagation to the final rupture.

Keywords: Mechanical behavior; Low alloy steel; Low cycle fatigue.

1 Engenharia Mecânica com ênfase em Automobilística, Centro Universitário da FEl, São Bernardo do Campo, São Paulo, Brasil.

2 Engenharia Industrial Mecânica, Mestre em Ciências, Professor, Engenharia de Materiais, Centro Universitário da FEI, São Bernardo do Campo, São Paulo, Brasil. 


\section{INTRODUÇÃO}

Um grande problema enfrentado por todos os materiais metálicos é a fadiga, onde, após solicitações cíclicas impostas, o material sofre ruptura. Por ser um processo de falha que ocorre sem um aviso prévio, é muito relevante que o projetista tenha conhecimento de qual a vida útil do material escolhido para determinada aplicação, evitando o inesperado e indesejado [1].

O aço NBR 6656 grau LNE 26, fornecido no formato de chapa, apresenta baixas resistência e dureza, alta tenacidade e ductilidade, uma boa conformabilidade e soldabilidade. Essas características fazem desse aço recomendável para estampagem, onde é necessária grande deformação plástica sem o risco de ruptura. Logo, é um material de muito interesse para as empresas automobilísticas, como também, para obtenção de perfis estruturais, placas para produção de tubos, dentre outras diferentes áreas e aplicações [2].

Esse trabalho tem o objetivo de investigar as relações entre o comportamento monotônico e cíclico com a resistência à fadiga, a hipótese é que se consiga estimar a equação de Basquin [1] sem a necessidade de um ensaio de fadiga completo.

Apresenta um levantamento da dureza pela espessura do corpo de prova e uma caracterização microestrutural para identificar as inclusões e conhecer os constituintes e fases presentes no aço, oferecendo informações importantes para futuras comparações e aplicações, bem como, ensaios monotônicos e cíclicos para levantamento das principais propriedades mecânicas do aço e suas relações. E por fim, uma análise fractográfica para determinar se o modo de falha desempenha um papel importante para esse tipo de comparação e se a aplicação dos dados do comportamento monotônico e cíclico para estimativa do comportamento a fadiga do material estudado é possível.

\section{MATERIAL E MÉTODOS}

\subsection{Material}

Foi utilizada uma chapa, parte de um estoque antigo, sem histórico de fornecimento, com espessura nominal de $4 \mathrm{~mm}$ nas dimensões de $365 \times 175 \mathrm{~mm}$ com composição química especificada segundo a tabela 1.

Tabela 1. Requisitos de composição química, dados em \% peso, para aço grau LNE 26 segundo ABNT NBR 6656 [2].

\begin{tabular}{lccccccc}
\hline AÇO & $\mathbf{C}$ & Mn & Si & $\mathbf{P}$ & $\mathbf{S}$ & $\mathbf{A l}$ & $\begin{array}{c}\text { Elementos } \\
\text { de liga }\end{array}$ \\
\hline $\mathrm{LNE}$ & $0,15^{\mathrm{A}}$ & 1,00 & 1,35 & 0,03 & 0,03 & $\geq 0,02$ & $\mathrm{~B}$ \\
26 & & & & \\
\hline (A) No caso de ser adicionado elemento de liga, o carbono deve ser reduzido a & $0,12 \%$ \\
(B) Nb máx. = 0,12\%; & Ti máx. = 0,20\%; $V$ máx. $=0,12 \%$ e 50,20 máx.
\end{tabular}

Para os ensaios de tração foram preparados os corpos de prova de acordo com a figura 1 e para os ensaios cíclicos, figura 2. Esses corpos de prova seguiram as especificações das normas ASTM E8 e E606 respectivamente [3, 4]. 


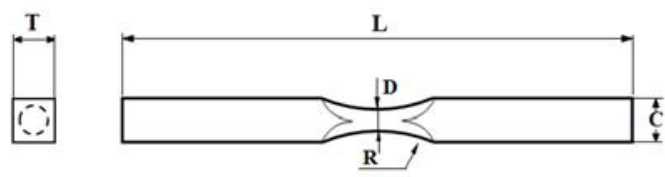

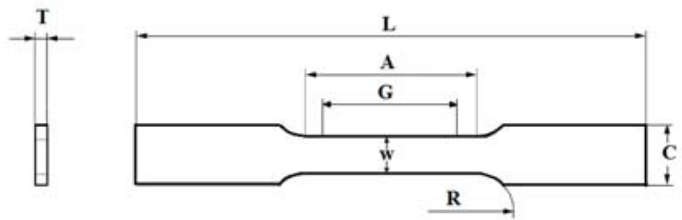

Figura 1. Corpo de prova para o ensaio de tração. Dimensões em milímetros: $L=170 \pm 0,5$, $A=57 \pm 0,5, G=50 \pm 0,1, W=R=12,5 \pm 0,2, C=20 \pm 0,2$ e T=4 $\pm 0,2$. (Adaptado de ASTM E 8M-2013).
Figura 2. Corpo de prova para o ensaio de fadiga (corpo de prova de seção circular lenticular). Dimensões em milímetros:

$L=170 \pm 0,5, D=3,8 \pm 0,2, R=24 \pm 0,2, C=T=4 \pm 0,2$. (Adaptado de ASTM E 606-2012).

\subsection{Ensaio de microdureza}

Por meio de um embutimento metalográfico e processos de polimento, foi feita uma amostra para utilizar-se em um microdurômetro, Shimadzu HMV2, em que foi utilizada a escala de dureza Vickers, HV0,5, conforme figura 3, ASTM E 384 [5].

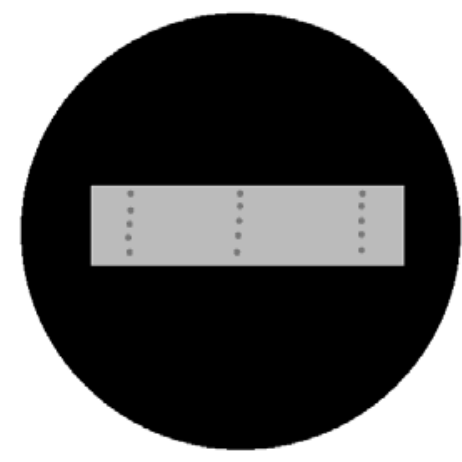

Figura 3. Desenho esquemático mostrando a amostra retirada da chapa, embutida e polida, com cinco penetrações feitas em cada uma das três regiões distintas.

\subsection{Caracterização microestrutural}

A caracterização foi feita em um microscópio ótico, Olympus, e em um microscópio eletrônico de varredura (MEV), CamScan 3200LV, para obter-se uma melhor observação da microestrutura.

Para a determinação do grau de inclusões a amostra foi observada em 20 campos com aumento de 100x, ASTM E 45 [6].

Após a análise das inclusões e sua caracterização, a amostra foi atacada quimicamente para determinação do tamanho médio de grão e as fases presentes na estrutura, ASTM E 112 [7]. O ataque químico foi feito com uma solução de nital $2 \%$ (980 $\mathrm{ml}$ de álcool etílico e $20 \mathrm{ml}$ de ácido nítrico).

\subsection{Ensaio de tração}

Foi feito o ensaio monotônico de acordo com a norma ASTM E8M-2013 e ASTM E 646-2007 [3,8], na máquina MTS, Material Test System 810, em três corpos de prova, figura 4 a. Foram utilizados dois extensômetros, um para deformação axial, usado para determinação do módulo de elasticidade $(E)$, e outro para deformação transversal utilizado para determinação do coeficiente de Poisson (v). 


\subsection{Ensaio cíclico e fadiga}

Para os ensaios cíclicos os corpos de prova da figura 2 foram submetidos a uma deformação, onda senoidal totalmente reversa com frequência de $1 \mathrm{~Hz}$, até a ruptura. Foram utilizados cinco níveis de deformação (ensaios de baixo ciclo) com pelo menos duas repetições em cada nível, o controle da deformação foi realizado por meio do uso de um extensômetro diametral, o qual, monitora a deformação transversal do corpo de prova e fornece o sinal para o controle do equipamento, figura $4 \mathrm{~b}$.

a)

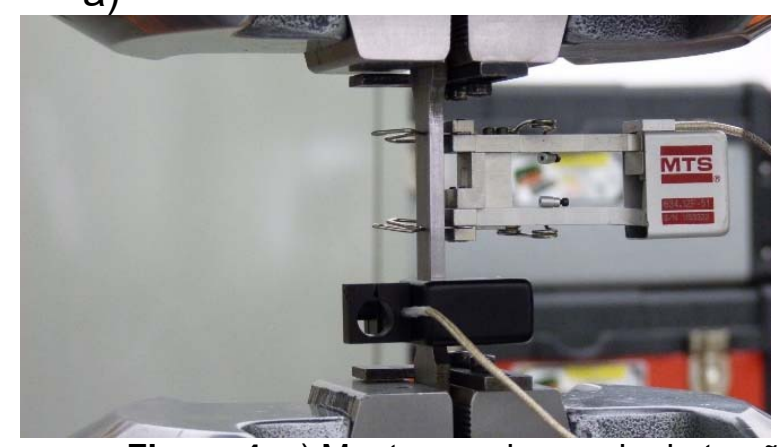

b)

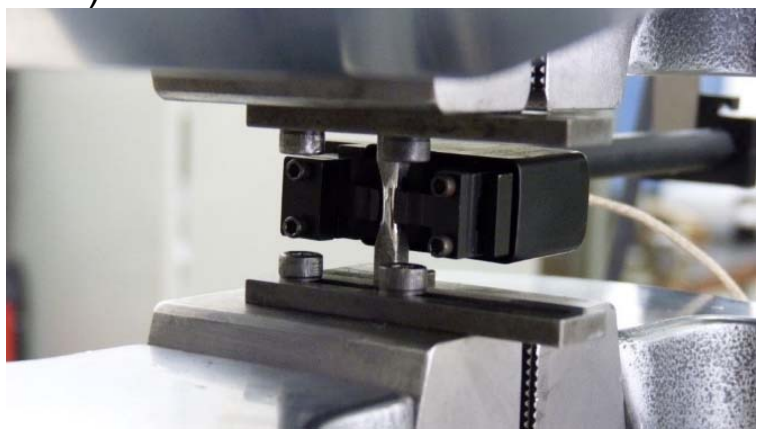

Figura 4. a) Montagem do ensaio de tração monotônico. b) Montagem do ensaio cíclico.

\subsection{Análise fractográfica}

Por meio do MEV realizou-se análises fractográficas com o objetivo de definir o modo de falha representativo para os corpos de prova testados em fadiga de baixo ciclo. Realizou-se também um corte transversal para avaliação de como se originou o dano por fadiga na seção transversal.

\section{RESULTADOS E DISCUSSÃO}

\subsection{Ensaio de microdureza}

Através do ensaio de microdureza foi levantado um gráfico que mostra o perfil de dureza pela espessura, como é mostrado na figura 4. Conclui-se que na região mais próxima à superfície, a dureza apresenta valores mais altos, e quando se aproxima do núcleo existe um decaimento em seu valor. Tal fato pode ser proveniente do processo de laminação que a chapa foi sujeita, pois, devido ao contato direto com os cilindros de laminação, a região de contato sofreu um trabalho a frio, aumentando a dureza devido a multiplicação de discordâncias ocorrida no encruamento. 


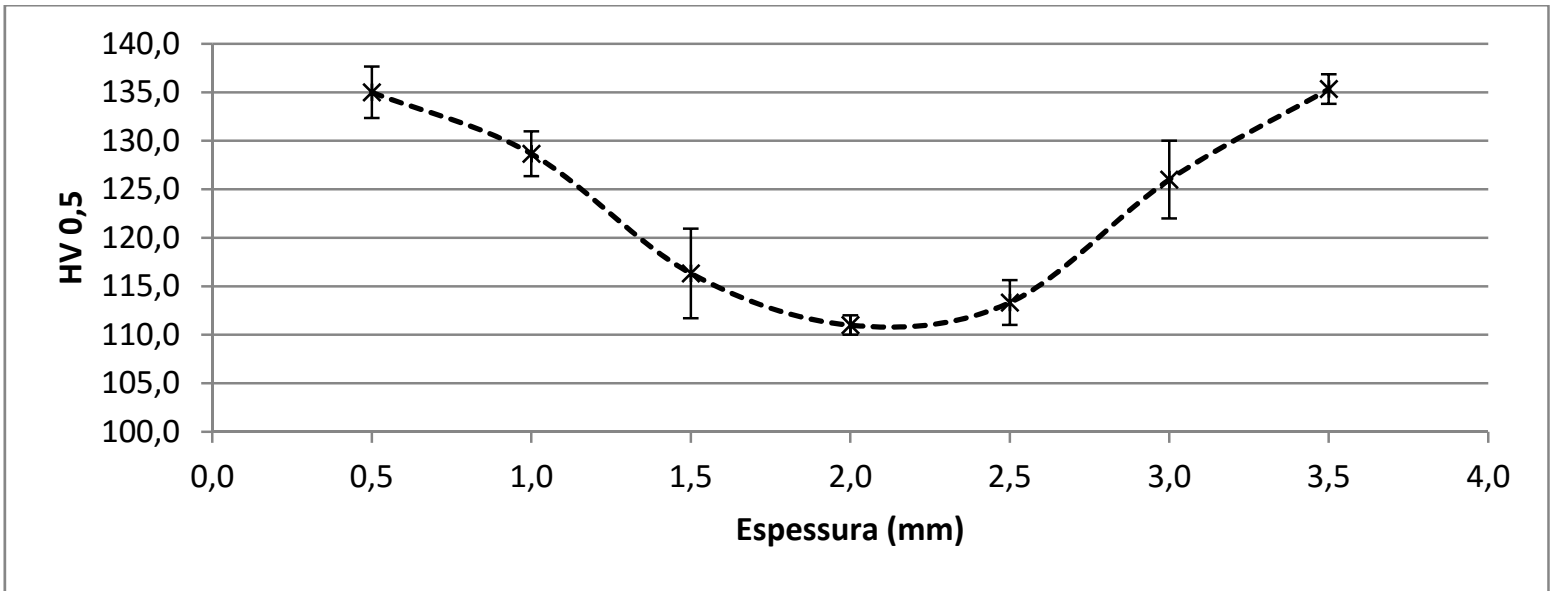

Figura 5. Gráfico do perfil da dureza pela espessura.

Este tipo de material, laminado a quente, e acabado através de uma pequena redução de espessura em um laminador acabador (também conhecido no meio como 'hot skin pass'), daí a diferença de dureza. Esta é uma condição conhecida da literatura e comercial para este tipo de aço e é feita para retirar o patamar de escoamento da curva de tração e homogeneizar seu comportamento mecânico.

\subsection{Caracterização microestrutural}

$\mathrm{Na}$ análise microestrutural, feita tanto no microscópio óptico quanto no eletrônico de varredura, foi constatado que o padrão apresentado pelas inclusões no caso mais crítico foi de inclusões do tipo de óxido globular fino, de série 11/2, e óxido globular grossa, de série 1.

Com a amostra atacada quimicamente (Nital 2\%), a microestrutura encontrada foi ferrita e perlita. O tamanho médio dos grãos $(G)$ foi medido e encontra-se entre 7,5 e 9,5 ASTM, figuras 5 a e b.

a)

b)

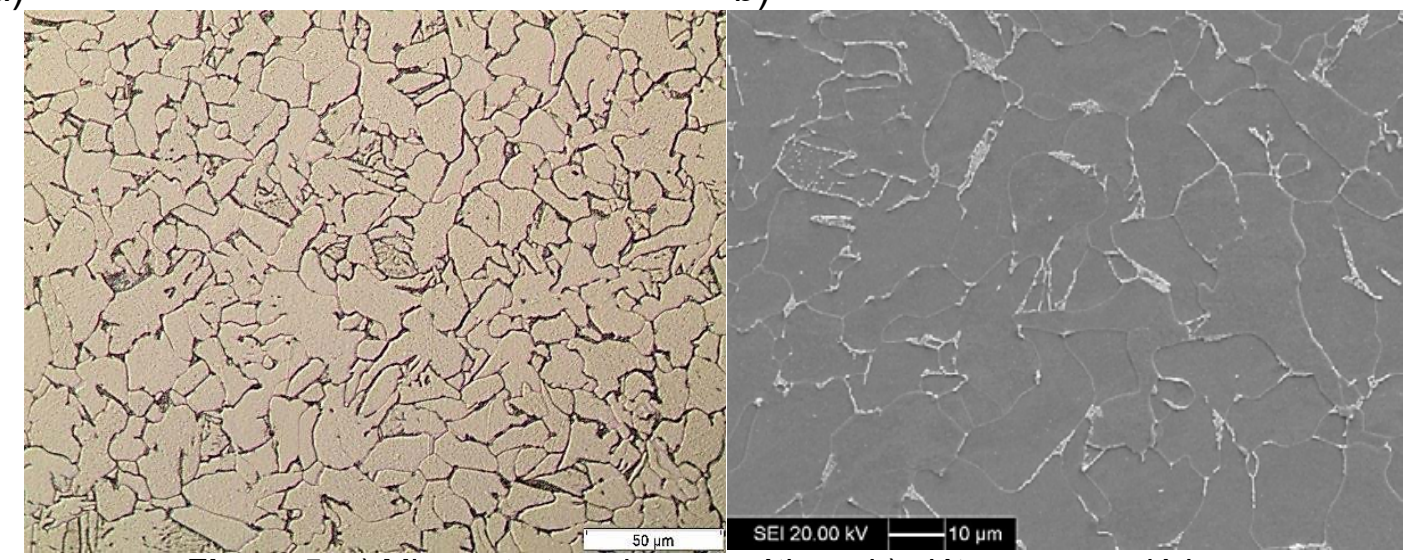

Figura 5. a) Microestrutura, imagem ótica e b) elétrons secundários.

\subsection{Ensaio de tração}

Por meio do ensaio de tração obtiveram-se as propriedades mecânicas do material estudado, vide tabela 2, do aço grau LNE 26, e segundo a norma [2], constata-se que os valores estão de acordo com a especificação. 
Tabela 2. Propriedades mecânicas obtidas a partir do ensaio de tração para três corpos de prova de seção retangular.

\begin{tabular}{|c|c|c|c|c|c|c|c|c|}
\hline $\begin{array}{l}\text { Corpos } \\
\text { de prova }\end{array}$ & $\begin{array}{c}\sigma_{\mathrm{e}} \\
(\mathrm{MPa})\end{array}$ & $\begin{array}{c}\sigma_{\mathrm{r}} \\
(\mathrm{MPa})\end{array}$ & $\begin{array}{l}\text { EL } \\
(\%)\end{array}$ & $\begin{array}{c}\mathrm{E} \\
(\mathrm{GPa})\end{array}$ & $n$ & $\begin{array}{c}\mathrm{H} \\
(\mathrm{MPa})\end{array}$ & $\begin{array}{l}R^{A A} \\
(\%)\end{array}$ & $v$ \\
\hline $\begin{array}{l}\text { Valores } \\
\text { médios }\end{array}$ & 314 & 392 & 36,1 & 215 & 0,1935 & 653 & 37 & 0,3102 \\
\hline
\end{tabular}

\subsection{Curva tensão-deformação cíclica}

Determinou-se o comportamento cíclico dos corpos de prova de seção lenticular na faixa de deformação axial de 0,0007 a 0,01, considerou-se a tensão como estabilizada após vinte ciclos e carregamentos totalmente reversos. Para comparação, também é apresentada a curva monotônica, conforme a figura 6 . Na tabela 3, são apresentados o coeficiente de resistência e o expoente de encruamento cíclicos.

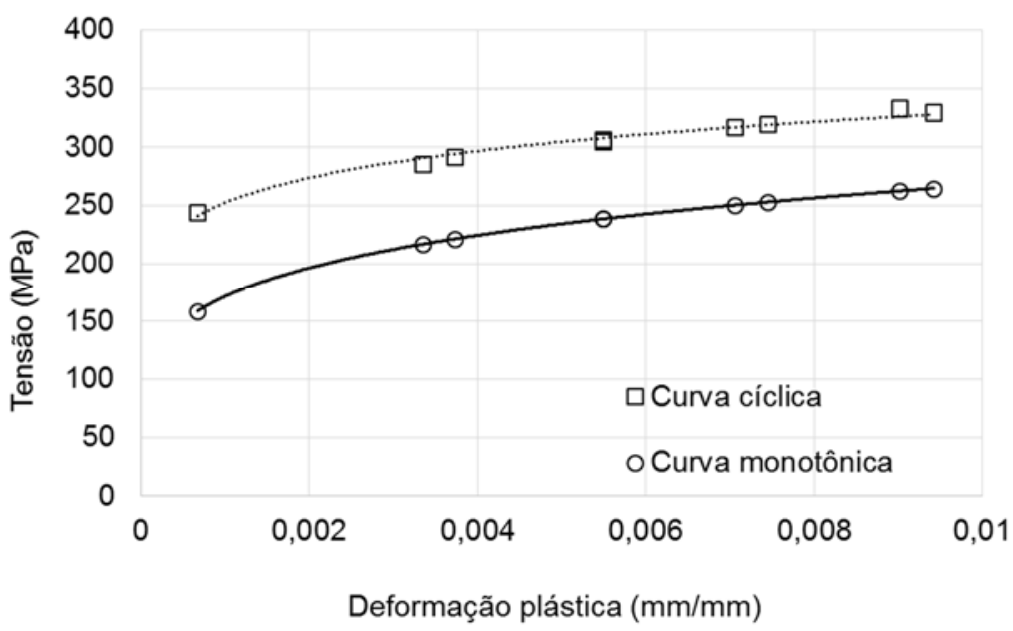

Figura 6. Curva cíclica e monotônica para valores médios de tensão e deformação cíclica obtida através do corpo de prova de seção lenticular para a faixa de deformação entre 0,0007 e 0,01.

Tabela 3. Valor do coeficiente de resistência cíclico $\left(H^{\prime}\right)$ e do expoente de encruamento cíclico ( $\left.n^{\prime}\right)$.

\begin{tabular}{cc}
\hline $\mathbf{H}^{\prime}$ & $\mathbf{n}^{\prime}$ \\
\hline 567 & 0,117 \\
\hline
\end{tabular}

Nota-se que o material apresentou um aparente endurecimento cíclico, pois, a curva cíclica apresenta maiores valores de tensão que a curva monotônica, no entanto, pode ter havido um efeito conjunto com a influência da taxa de deformação, uma vez que o ensaio monotônico é realizado com taxas menores que o ensaio cíclico, onde a frequência foi de $1 \mathrm{~Hz}$. O ideal seria utilizar o primeiro ciclo de carregamento em fadiga, mas esse dado não foi disponibilizado.

\subsection{Ensaio de fadiga}

Obteve-se as curvas de fadiga por meio da amplitude de deformação elástica e plástica, até a falha, tabela 4 , e por meio dos dados obtidos no ensaio cíclico, considerando-se a estabilização da tensão com 20 ciclos, tabela 5. 
Tabela 4. Valores obtidos pelo ensaio de fadiga.

$\begin{array}{ccccc}\boldsymbol{\sigma}_{\mathbf{f}}^{\prime} & \mathbf{b} & \boldsymbol{\varepsilon}_{\mathbf{f}}^{\prime} & \mathbf{C} & \begin{array}{c}\mathbf{N}_{\mathbf{t}}^{\mathbf{A}} \\ \text { (ciclos) }\end{array} \\ 542 & -0,07 & 0,651 & -0,591 & 21346\end{array}$

A - Número de ciclos para transição de fadiga de baixo ciclo para fadiga de alto ciclo. Fonte: Do autor.

Tabela 5. Valores obtidos pelo comportamento cíclico (tensão estabilizada com 20 ciclos).

\begin{tabular}{ccccc}
\hline $\boldsymbol{\sigma}_{\mathbf{f}}$ & $\mathbf{b}$ & $\boldsymbol{\varepsilon}_{\mathbf{f}}^{\prime}$ & $\mathbf{C}$ & $\begin{array}{c}\mathbf{N}_{\mathbf{f}}^{\mathbf{A}} \\
\text { (ciclos) }\end{array}$ \\
\hline 563 & $-0,074$ & 0,95 & $-0,631$ & 19697 \\
\hline
\end{tabular}

A - Número de ciclos para transição de fadiga de baixo ciclo para fadiga de alto ciclo. Fonte: Do autor.

Observa-se por meio das figuras 7 e 8 , que os dados obtidos com os ensaios para caracterização do comportamento cíclico até a estabilização da tensão (20 ciclos), encomtram-se dentro da faixa superior e inferior do tratamento estatístico para os dados obtidos do ensaio de fadiga até a falha [9].

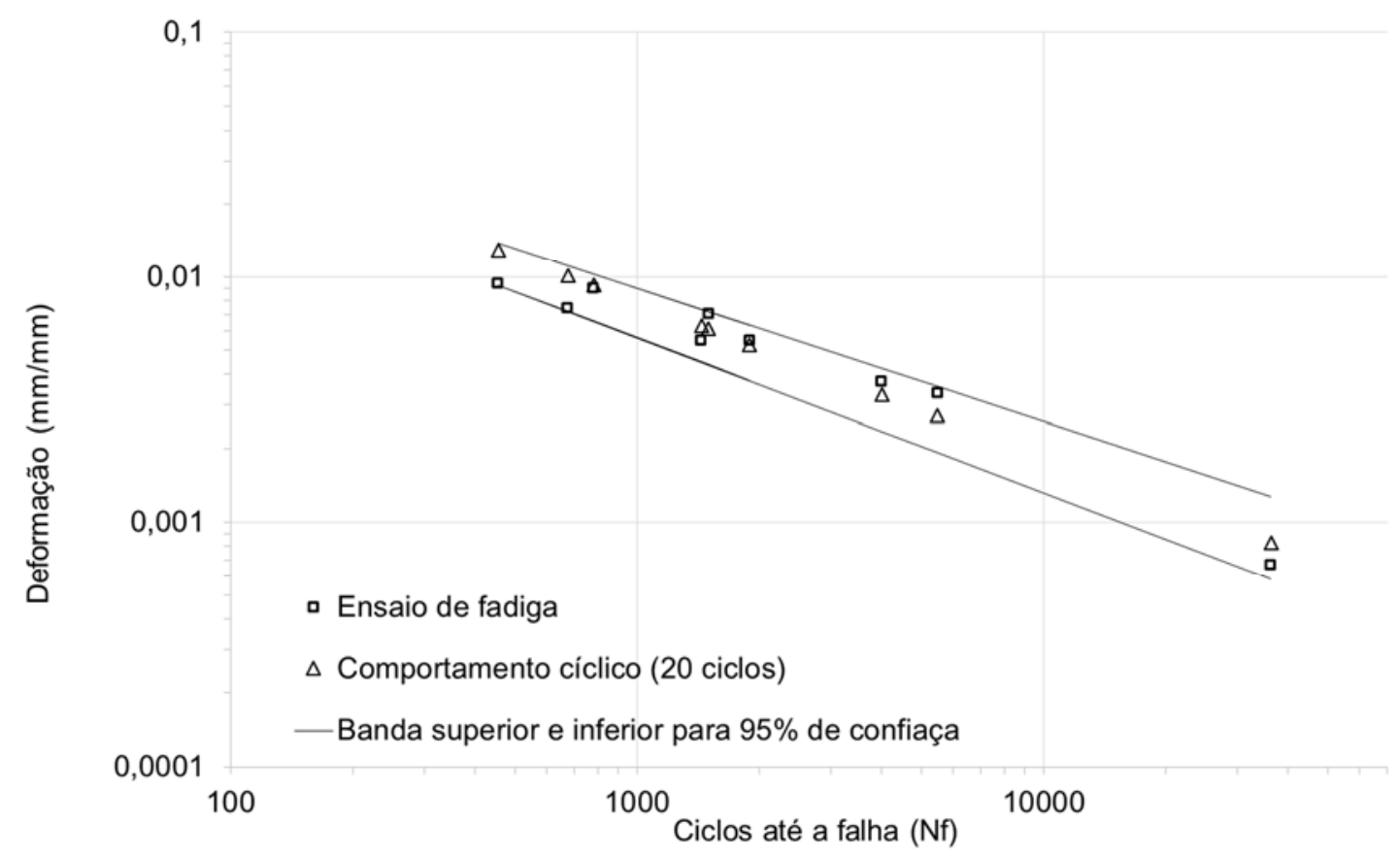

Figura 7. Vida em fadiga para o corpo de prova lenticular em função da deformação plástica. 


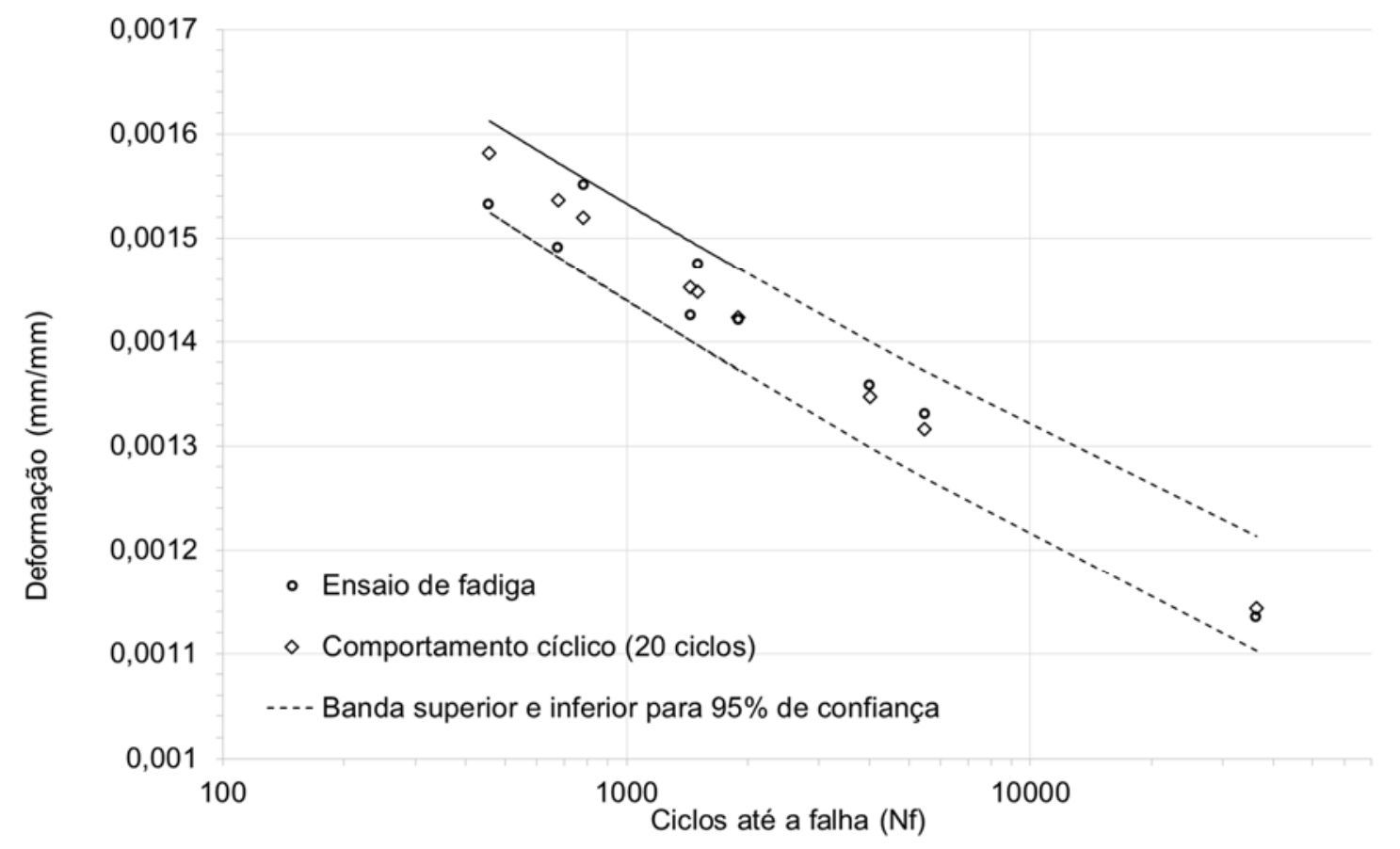

Figura 8. Vida em fadiga para o corpo de prova lenticular em função da deformação elástica.

\subsection{Análise fractográfica}

Examinando-se as fraturas dos corpos de prova lenticulares com o auxílio do microscópio eletrônico de varredura (MEV) foi possível identificar como foi o comportamento do material a partir da nucleação de uma trinca e sua propagação, até a fase de rompimento completo da seção transversal, figura 8 .

Observa-se especificamente três regiões distintas da seção transversal do corpo de prova após sua fratura por fadiga. Nota-se que as trincas se iniciaram na superfície entre a interface ferrita-cementita, mostrado pela seta, figuras a e b, em seguida houve propagação transgranular, mostrado pela seta, figuras $\mathrm{c}$ e d, e finalmente ruptura por tração figuras e e f.

Nota-se que as trincas se iniciaram na superfície entre a interface ferrita - cementita, em seguida houve propagação transgranular, e finalmente ruptura por tração.

Comparando-se esse comportamento com o do aço bifásico DP 600 [10], nota-se uma semelhança no modo de falha, a ocorrência de trincas na interface ferrita-martensita e posterior fratura transgranular. Assim, ambos os aços ensaiados com fadiga de baixo ciclo sofreram inicialmente a degradação na interface entre uma fase com alta resistência e frágil e a outra com baixa resistência e dúctil possivelmente devido a incompatibilidade plástica entre essas fases. 

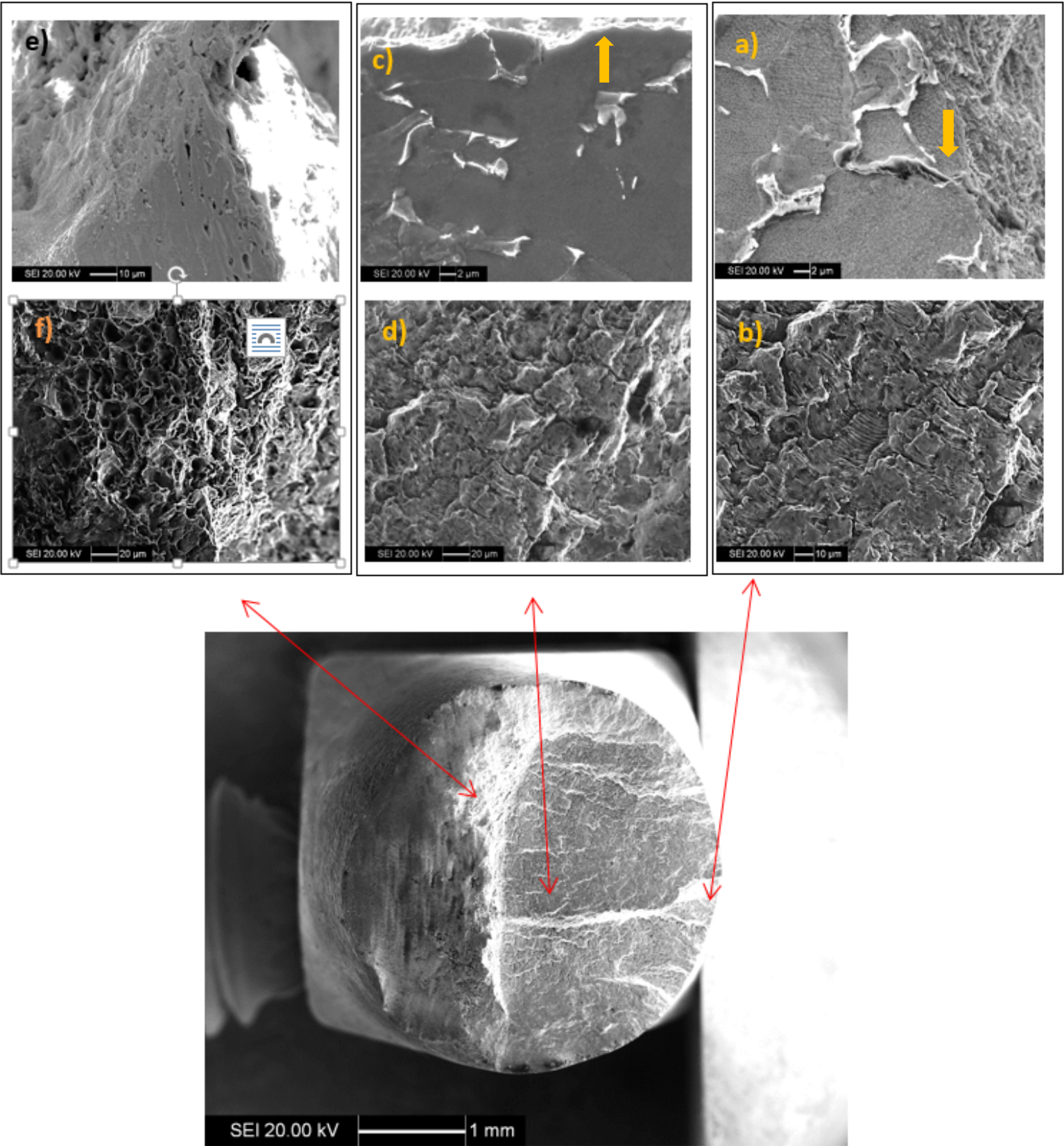

Figura 9. Regiões de fratura do corpo de prova (MEV).

\section{CONCLUSÕES}

Constatou-se que a dureza da chapa fornecida para o trabalho não é uniforme, devido ao processo de laminação, sua superfície apresenta um valor de dureza maior do que no centro.

O grau de inclusões e as fases presentes são compatíveis para o material estudado. As propriedades mecânicas monotônicas do aço grau LNE 26 estão de acordo com o especificado pela norma ABNT NBR 6656 [2].

A equação obtida com os valores dos ensaios cíclicos até 20 ciclos (estabilização da tensão) encontra-se dentro da faixa superior e inferior da equação obtida do ensaio de fadiga de baixo ciclo até a falha.

A partir da análise fractográfica do material após o ensaio de fadiga, observou-se que a falha ocorreu devido à nucleação de trincas na interface ferrita-cementita e posterior 
propagação transgranular percorrendo a seção transversal do material e levando o aço à ruptura por tração após redução significativa da seção transversal.

\section{Agradecimentos}

Ao Centro Universitário da FEI pela oportunidade de realização desta iniciação científica (PBIC).

\section{REFERÊNCIAS}

1 CALLISTER, WILLIAM D. Materials science and engineering: An introduction. 7ed. University of Utah, 2007.

2 ABNT NBR 6656: Chapas e bobinas de aço acalmado com características especiais de propriedades mecânicas, conformabilidade e soldabilidade, 1992.

3 AMERICAN SOCIETY FOR TESTING AND MATERIALS, ASTM E 8M-13: Standard test methods for tension testing of metallic materials [Metric]. Philadelphia, 2013.

4 AMERICAN SOCIETY FOR TESTING AND MATERIALS, ASTM E 606M-12: Standart practice for strain-controlled fatigue testing. Philadelphia, 2012.

5 AMERICAN SOCIETY FOR TESTING AND MATERIALS, ASTM E 384-11: Standard Test Method for Microindentation Hardness of Materials. Philadelphia, 2011.

6 AMERICAN SOCIETY FOR TESTING AND MATERIALS, ASTM E 45-11: Standard Test Methods for Determining the Inclusion Content of Steel. Philadelphia, 2011.

7 AMERICAN SOCIETY FOR TESTING AND MATERIALS, ASTM E 112-13: Standard test method for determining average grain size. Philadelphia, 2013.

8 AMERICAN SOCIETY FOR TESTING AND MATERIALS, ASTM E 646-07: Standart test method for tensile strain-hardening exponents ( $n$-values) of metallic sheet materials. Philadelphia, 2007.

9 AMERICAN SOCIETY FOR TESTING AND MATERIALS, ASTM E 739-10: Standard Practice for Statistical Analysis of Linear or Linearized Stress-Life (S-N) and Strain-Life $(\varepsilon-N)$ Fatigue Data. Philadelphia, 2010.

10 NAVILLE, W. Influência da Geometria de Corpos-de-prova na Previsão de Vida em Fadiga de Baixo Ciclo de Chapas de Aço (ARBL) bifásicos. 2009. 123 f. Tese (Mestrado em Física e Química dos Materiais Aeroespaciais) - Instituto Tecnológico de Aeronáutica, São José dos Campos. 